\title{
Alzheimer's Disease, Oestrogen and Mitochondria: an Ambiguous Relationship
}

\author{
Amandine Grimm • Yun-An Lim • \\ Ayikoe Guy Mensah-Nyagan • Jürgen Götz • \\ Anne Eckert
}

Received: 16 March 2012 / Accepted: 21 May 2012 / Published online: 8 June 2012

(C) The Author(s) 2012. This article is published with open access at Springerlink.com

\begin{abstract}
Hormonal deficit in post-menopausal women has been proposed to be one risk factor in Alzheimer's disease (AD) since two thirds of AD patients are women. However, large treatment trials showed negative effects of long-term treatment with oestrogens in older women. Thus, oestrogen treatment after menopause is still under debate, and several hypotheses trying to explain the failure in outcome are under discussion. Concurrently, it was shown that amyloid-beta (A $\beta$ ) peptide, the main constituent of senile plaques, as well as abnormally hyperphosphorylated tau protein, the main component of neurofibrillary tangles, can modulate the level of neurosteroids which notably represent neuroactive steroids synthetized within the nervous system, independently of peripheral endocrine glands. In this review, we summarize the role of neurosteroids especially that of oestrogen in $\mathrm{AD}$ and discuss their potentially neuroprotective effects with specific regard to the role of oestrogens on the maintenance and function of mitochondria, important organelles which are highly vulnerable to $A \beta$ - and tau-induced toxicity. We also discuss the role of $A \beta$-binding alcohol dehydrogenase (ABAD), a mitochondrial enzyme able to bind $A \beta$ peptide
\end{abstract}

\footnotetext{
A. Grimm • A. Eckert $(\bowtie)$

Neurobiology Laboratory for Brain Ageing and Mental Health, Psychiatric University Clinics, University of Basel,

CH-4012 Basel, Switzerland

e-mail: anne.eckert@upkbs.ch
}

\author{
A. Grimm • A. G. Mensah-Nyagan \\ Equipe Steroïdes, Neuromodulateurs et Neuropathologies, \\ Unité de Physiopathologie et Médecine Translationnelle, \\ EA-4438, Université de Strasbourg, Faculté de Médecine, \\ 67000 Strasbourg, France \\ Y.-A. Lim • J. Götz \\ Centre for Ageing Dementia Research (CADR), \\ Queensland Brain Institute (QBI), The University of Queensland, \\ St Lucia Campus, \\ Brisbane, QLD 4072, Australia
}

thereby modifying mitochondrial function as well as oestradiol levels suggesting possible modes of interaction between the three, and the potential therapeutic implication of inhibiting $\mathrm{A} \beta-\mathrm{ABAD}$ interaction.

Keywords Alzheimer's disease · Neurosteroids · Oestrogen $\cdot$ Mitochondria $\cdot$ ABAD

\section{Introduction}

Steroid hormones are molecules, mainly produced by endocrine glands such as the adrenal gland, gonads and placenta, involved in the control of many physiological processes mainly in the periphery, from reproductive behaviour to stress response. In 1981, Baulieu and co-workers were the first to demonstrate steroid production within the nervous system itself [1]. They showed that the level of some steroids, such as dehydroepiandrosterone (DHEA), was even four times higher in the anterior brain of rats than in plasma and nearly 18 times higher than in the posterior brain with regard to its sulphated form (DHEAS). Of note, the level of this steroid remained elevated in the brain even after adrenalectomy and castration. In the following decades, other steroids were identified to be synthetized in situ in the brain, and enzymatic activities of proteins involved in steroidogenesis have been shown in many regions of the central and peripheral nervous system, in neurons as well as in glial cells [2-5]. Thus, this category of molecules is now called "neurosteroids" and defines neuroactive steroids that are synthetized within the nervous system, independently of peripheral endocrine glands. While steroid hormones act at a distance from their glands of origin in an endocrine way, neurosteroids are synthetized by the nervous system and act on the nervous system in an auto/paracrine configuration. 
Because of their lipophilic nature, peripheral steroid hormones can freely cross cell membranes, including the blood-brain barrier, and play an important role in the development, maturation and differentiation of the central and peripheral nervous system. However, since some steroids are also synthetized within the nervous system, their blood levels do not necessarily correspond to their brain concentrations [6]. Intra-cerebral steroid synthesis seems to play a role in cognition, anxiety, depression, neuroprotection and even nociception [7].

The ability to cross cellular membranes allows them to act on nuclear receptors exhibiting genomic action by regulating gene transcription. This action seems to be important during neonatal life where it has been shown that neurosteroids, such as progesterone (PROG) or oestradiol, are able to promote dendritic growth, spinogenesis, synaptogenesis and cell survival, particularly in the cerebellum [5]. Some studies already demonstrated the role of neurosteroids, particularly oestrogens, in the regulation of glucose homeostasis and lipid metabolism [8] as well as in neuroprotection [9]. Risk for Alzheimer's disease (AD) is associated with age-related loss of sex steroid hormones in both women and men $[10,11]$. On the one hand, in postmenopausal women, the precipitous depletion of oestrogens and progestogens is hypothesized to increase susceptibility to AD pathogenesis, a concept largely supported by epidemiological evidence but refuted by some clinical findings, above all, by results from the "Woman's health initiative memory study" (WHIMS) (please see detailed discussion in the "Conclusion" section). On the other hand, a growing body of evidence indicates a more gradual age-related decline in testosterone in men similarly associated with increased risk to several diseases including AD. Since testosterone is at least in part aromatized in the brain to $17 \beta$-oestradiol, a loss of it may also affect oestrogenmediated neuroprotective pathways. But also, the difference between how rapidly and significantly the female versus male primary sex hormones decline might partially contribute to higher $\mathrm{AD}$ incidences in women than in men [10].

\section{Alzheimer's Disease, Oxidative Stress, Effect of Gender and Neogenesis of Neurosteroids}

$\mathrm{AD}$ is a neurodegenerative brain disorder and the most common form of dementia among the elderly as shown by the worldwide prevalence of the disease which was 26.6 million people in 2006 [12]. Clinical symptoms are characterized by severe and progressive loss of memory, language skills as well as spatial and temporal orientation. From a cellular point of view, the pathological hallmark of $\mathrm{AD}$ is the presence of extracellular senile plaques - composed of aggregated amyloid- $\beta$ peptide $(A \beta)$-and intracellular neurofibrillary tangles (NFT) - consisting of aggregates of abnormally hyperphosphorylated tau protein. A lot of efforts have been made during the last years to understand the pathogenesis of the disease, particularly the role of $\mathrm{AD}$ key proteins, $A \beta$ and tau, in oxidative stress and mitochondrial dysfunction [13].

Epidemiological and observational studies demonstrated a higher prevalence and incidence of $\mathrm{AD}$ in women even after adjusting for age - about two thirds of AD patients are female - as well as a greater vulnerability to the disease [14]. Thus, at early stages of neurofibrillary tangle development, women exhibit greater senile plaque deposition than men [15], and AD pathology is more strongly associated with clinical dementia in female patients than in male [16]. The drop of oestrogen levels after menopause was proposed to be one explanation to this phenomenon. However, there is little information concerning changes of steroid levels in the human brain during ageing and under dementia conditions. As steroids present in nervous tissues originate from the endocrine glands (steroid hormones) and from local synthesis (neurosteroids), changes in blood levels of steroids with age do not necessarily reflect changes in their brain levels. The concentrations of a range of neurosteroids have recently been measured in various brain regions of aged $\mathrm{AD}$ patients and aged non-demented controls including both genders by the very sensitive GC/MS methods [6]. Schumacher and colleagues showed a general trend towards lower level of steroids including oestrogen in $\mathrm{AD}$ patients compared to controls. Notably, neurosteroid levels were negatively correlated with $A \beta$ and phospho-tau in some brain regions [6]. Another study using radioimmunoassay for steroid quantification demonstrated a decrease in oestrogen level in postmortem brain from female AD patients aged 80 years and older but no significant difference in the 60-79-year age range compared to non-demented women [17]. However in men, an age-dependent decrease of androgen level was observed in the brain of non-demented subjects, which was even more pronounced in the brain of male $\mathrm{AD}$ patients [17]. Whereas large studies investigating systematically gender differences with respect to $A \beta$ and or tau pathology in post-mortem brain tissue from $\mathrm{AD}$ patients are missing, broad evidence emerged from transgenic mice models of $\mathrm{AD}$ indicating an increased $\mathrm{A} \beta$ load burden and plaque number in the female brain compared to age-matched male mouse brain $[11,18]$. Of note, consistent findings on greater $\mathrm{A} \beta$ burden in females were found in different animal $\mathrm{AD}$ models: Tg2576 (APPSWE) mice [19], APP/PS1 [20], APP23 [21], as well as in triple transgenic mice, like 3xTg-AD mice $[18,22]$ and ${ }^{\text {triple }} \mathrm{AD}$ mice ([23], with respect to gender differences: unpublished observations). On the basis that the estrous cycle in female mice is constantly repeated until approximately 11 months of age and becomes irregular between 12 and 14 months, the data demonstrating 
a significant enhancement of $A \beta$ load in important brain regions like the hippocampus from the female after the age of 11 months are striking. Regarding tau pathology, no gender differences have been observed in the latter triple $\mathrm{AD}$ models. In agreement, NFT formation in A $\beta$-injected tau transgenic mice (P301L) did not vary with gender [24]. Even though one single publication reported an enhanced neurofibrillary pathology in female TAPP mice [25], all together, these results point to the involvement of the $A \beta$ pathway, rather than the tau pathway, in the higher risk of $\mathrm{AD}$ in women.

Interestingly, further supporting evidence comes from oxidative stress studies. Previous research of our group [26] demonstrated a gender-specific partial up-regulation of antioxidant defence in post-mortem brain regions from female compared to male $\mathrm{AD}$ patients further indicating that oxidative damage is caused rather by overproduction from reactive oxygen species (ROS) than by insufficient detoxification of ROS. Since mitochondria represent the major source of ROS, the findings from Lloret and co-workers are of specific interest showing that brain mitochondria from old female rats produce higher levels of ROS after exposure to $A \beta$ than age-matched brain mitochondria from male rats [27].

A selection of studies attested neuroprotective effects of neurosteroids against AD-related cellular and mitochondrial injury, but the underlying mechanisms are still poorly understood.

Findings of our group corroborated that AD key proteins and oxidative stress are themselves able to modify neogenesis of neurosteroids in a cellular AD model [28, 29] (Fig. 1). In fact, treatment of human SH-SY5Y neuroblastoma cells with
$\mathrm{H}_{2} \mathrm{O}_{2}$ for 24 or $48 \mathrm{~h}$ led to a decrease of oestradiol synthesis. This was paralleled by an increased cell death compared to untreated controls and a down-regulation of the expression of aromatase, an enzyme responsible for oestradiol formation from testosterone. Interestingly, cell death was also observed after inhibition of aromatase by treatment with letrozole, suggesting that endogenous oestradiol formation plays a critical role in cell survival. Furthermore, if cells were pre-treated with oestradiol, it was possible to protect them against $\mathrm{H}_{2} \mathrm{O}_{2}$ and letrozole-induced cell death. In agreement, a similar protective effect of oestradiol was observed in stress condition experiments treating the same cell line with heavy metals, such as cobalt and mercury [30].

In addition, modulation of neurosteroid production was observed in SH-SY5Y cells overexpressing the human amyloid processor protein (APP) or human tau protein [28]. Indeed, overexpression of human wild-type Tau (hTau 40) protein induced an increase in the production of PROG, $3 \alpha-$ androstanediol and 17-hydroxyprogesterone, in contrast to overexpression of the abnormally hyperphosphorylated tau bearing the P301L mutation which led to a decrease in the production of these neurosteroids. In parallel, a decrease of PROG and 17-hydroxyprogesterone production was observed in cells expressing human wild-type APP (wtAPP), whereas $3 \alpha$-androstanediol and oestradiol levels were increased. These results provided first evidence that AD key proteins are able to modulate, directly or indirectly, the biological activity of the enzymatic machinery producing neurosteroids. These findings were further confirmed by in vitro experiments using native SH-SY5Y cells treated with aggregated $A \beta_{1-42}$ peptide for $24 \mathrm{~h}$ [31]. Since APPwt SH-

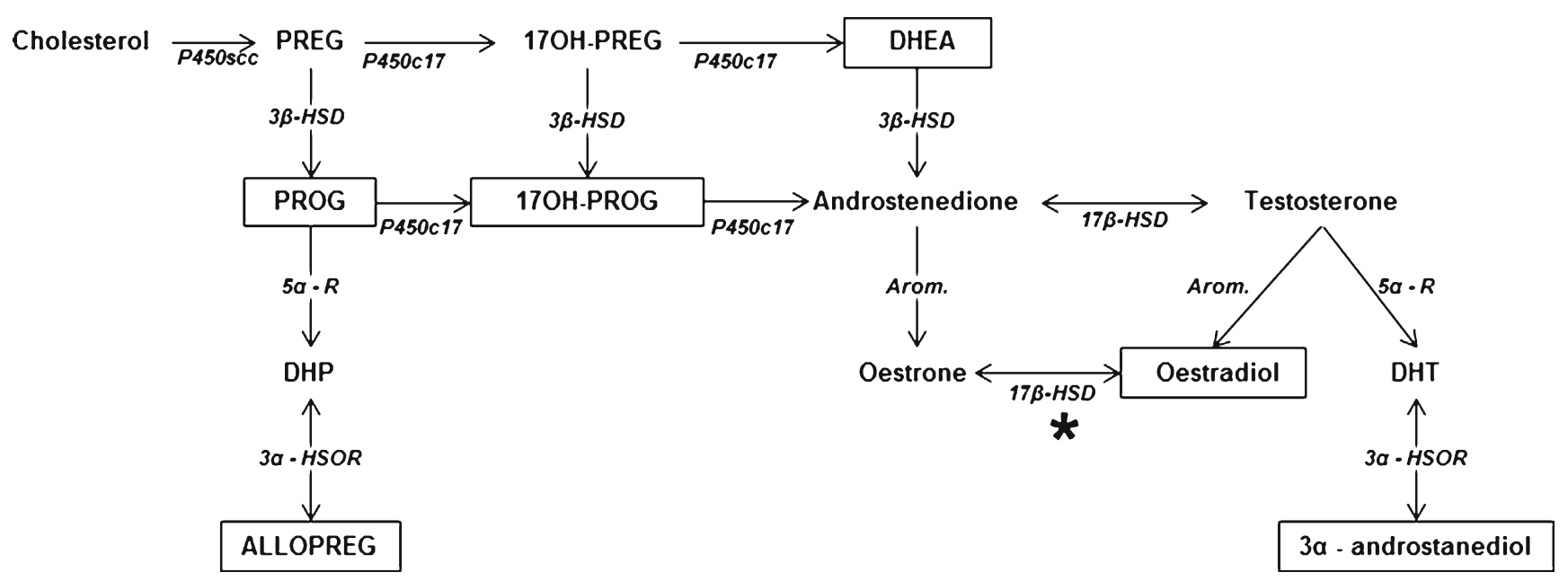

Fig. 1 Main biochemical pathways for neurosteroidogenesis in the vertebrate brain. Boxes represent neurosteroids which are sensitive to modulation by $\mathrm{AD}$ key proteins, $\mathrm{A} \beta$ and/or tau. Mitochondrial $17 \beta-\mathrm{HSD}$ $($ marked by $*$ ) is equivalent to the $\mathrm{ABAD}$ in mitochondria. $P R E G$ pregnenolone, $P R O G$ progesterone, 17OH-PREG 17-hydroxypregnenolone, 17OH-PROG 17-hydroxyprogesterone, DHEA dehydroepiandrosterone,
DHP dihydroprogesterone, ALLOPREG allopregnanolone, DHT dihydrotestosterone, $P 450$ scc cytochrome P450 cholesterol side chain cleavage, $P 450 c 17$ cytochrome P450c17, 3 $\beta$-HSD $3 \beta$-hydroxysteroid dehydrogenase, $5 \alpha-R 5 \alpha$-reductase, Arom. aromatase, 21-OHase 21-hydroxylase, $3 \alpha$-HSOR $3 \alpha$-hydroxysteroid oxydoreductase, $17 \beta$-HSD $17 \beta$ hydroxysteroid dehydrogenase 
SY5Y cells secrete $A \beta$ levels within nanomolar concentration range, treatment of native SH-SY5Y cells using a "nontoxic" concentration range $(100-1,000 \mathrm{nM}$, non-cell deathinducing $A \beta_{1-42}$ concentrations) revealed an increase in oestradiol production, whereas toxic $A \beta_{1-42}$ concentrations within the micromolar range, leading to cell death, strongly reduced oestradiol levels.

Modulation of steroid production was also shown in other cell lines, for example in oligodendrocytes, where DHEA production is up-regulated under oxidative stress condition induced by treatment with $\mathrm{A} \beta$ peptide or $\mathrm{Fe}^{2+}$ [32]. Interestingly, similar results were found in Alzheimer patients where DHEA was significantly elevated in brain and cerebrospinal fluid when compared to control subjects [33]. Finally, several reports propose the role of allopregnanolone $(3 \alpha, 5 \alpha$-THP) as a plasmatic biomarker for $\mathrm{AD}$, since it was shown that the level of this neurosteroid is decreased by $25 \%$ in the plasma of demented patients compared with control subjects [34, 35].

The fact that the ability to produce neurosteroids is conserved in the vertebrates' evolution suggests that this category of molecules is important for living beings. Thus, we could speculate that the modulation of their biosynthesis plays an important role in the pathophysiology of neurodegenerative disorders, such as $\mathrm{AD}$.

\section{Neurosteroids, Especially Oestrogens, and Neuroprotection in AD}

Evidence of Neuroprotective Action of Steroids in Cellular and Animal Studies

Neuroprotective effects of neurosteroids against a variety of brain injuries have already been described for many years. Numerous studies with the focus on oestrogens showed that these molecules are able to enhance cerebral blood flow, prevent atrophy of cholinergic neurons, and modulate the effects of trophic factors in the brain [36]. Oestrogens are a group of compounds known for their importance in the estrous cycle including oestrone (E1), oestradiol (E2), and oestriol (E3). Oestradiol is about ten times as potent as oestrone and about 80 times as potent as oestriol in its oestrogenic effect. Oestradiol is also present in males, being produced as an active metabolic product of testosterone. The serum levels of oestradiol in males $(14-55 \mathrm{pg} / \mathrm{mL})$ are roughly comparable to those of post-menopausal women $(<35 \mathrm{pg} / \mathrm{mL})$. Oestradiol in vivo is interconvertible with oestrone, oestradiol to oestrone conversion being favoured; however, evidence of metabolism is mainly derived from the periphery.

Animal studies, especially in rodents and transgenic mice models for $\mathrm{AD}$, seem to confirm positive effects of oestrogen treatment. It has been shown that a treatment with oestrogen in mice expressing mutations in human APP (Swedish and Indiana mutation) had an impact on APP processing decreasing $A \beta$ levels and so its aggregation into plaques [37]. Mechanisms underlying this action of oestrogen are still poorly understood, but as discussed by Pike et al. [11], it seems that oestrogen amongst others is able to promote the $\alpha$-secretase pathway (non-amyloidogenic, meaning non-A $\beta$ producing) via activation of extracellular-regulated kinase 1 and 2 (ERK 1 and 2) and through the protein kinase C (PKC) signalling pathway.

In triple transgenic $\mathrm{AD}$ mice, depletion in sex steroid hormones induced by ovariectomy in adult females increased significantly $A \beta$ accumulation and had a negative impact on cognitive performance $[18,38]$. Treatment of these ovariectomized mice with oestrogens was able to prevent these effects vice versa. Of note, when PROG was administrated in combination with oestrogens, the beneficial effects on $A \beta$ accumulation were blocked but not on cognitive performance. However, oestrogen and PROG both can modulate kinase and phosphatase activity involved in tau phosphorylation, especially the glycogen synthase kinase- $3 \beta$ (GSK-3 $\beta$ ). Thus, oestrogen can induce the phosphorylation of GSK-3 $\beta$ which inactivates the enzyme and reduces tau phosphorylation, whereas PROG can decrease the expression of tau and GSK-3 $\beta[11,39]$. This suggests that oestrogen and PROG not only can interact to regulate APP processing and tau phosphorylation but can also act independently on different $\mathrm{AD}$ pathways.

Cognitive effects of PROG were confirmed in mice bearing the Swedish double mutation of APP and mutant preseniline 1 (APPswe+PSEN1 $\Delta 9$ mutant mice) which showed decreased hippocampally mediated cognitive performances compared to non-transgenic littermates [38]. In this $\mathrm{AD}$ mouse model, PROG was able to improve the cognitive performance in tasks involving the cortex but not in those involving the hippocampus. Besides, APPswe $+\operatorname{PSEN} 1 \Delta 9$ mice presented decreased $3 \alpha, 5 \alpha$-THP levels (metabolite of PROG) in the hippocampus, compared to wild-type mice, suggesting that deficits in hippocampal function may be due, at least in part, to reduced capacity to form $3 \alpha, 5 \alpha$ THP in the hippocampus. Furthermore, a more recent study supported the role of $3 \alpha, 5 \alpha$-THP in triple transgenic mice model of $\mathrm{AD}(3 \mathrm{xTgAD})$ by showing reduced $\mathrm{A} \beta$ generation in the hippocampus, cortex and amygdala, coupled with an increased cellular regeneration after treatment with $3 \alpha, 5 \alpha$ THP [40].

At the cellular level, oestrogen binds to nuclear receptors, such as oestrogen receptor $\alpha$ and $\beta(\operatorname{ER} \alpha / \beta)$, and acts as transcription factor. It enhanced the expression of antiapoptotic proteins, such as Bcl-2 and Bcl-xL, and downregulated the expression of Bim, a pro-apoptotic factor, preventing the initialisation of cell death programme by 
mitochondria [11, 41]. Another way that oestrogen can protect cells from apoptosis is the activation of antioxidant defence systems by up-regulating the expression of manganese superoxide dismutase (MnSOD) and glutathione peroxidase [42]. Thus, oestrogen can have direct antioxidant effects by increasing reduced glutathione levels and decreasing oxidative DNA damage in mitochondria, as observed in a study using ovariectomized female rats [43]. Of note, oestrogen can also modulate the redox state of cells by intervening with several signalling pathways, such as mitogen-activated protein kinase (MAPK), G protein-regulated signalling, NFkB, c-fos, CREB, phosphatidylinositol-3-kinase, PKC and $\mathrm{Ca}^{2+}$ influx [41, 44]. On the basis of this complex mode of action, oestrogens not only seem to be able to decrease oxidative stress markers, including lipid peroxidation, protein oxidation and DNA damage, but can also directly act on the regulation of mitochondrial function [42].

Neurosteroids and Mitochondria: Focus on Potential Protective Effects of Oestrogen Against $A \beta$-Induced Toxicity

Mitochondria are the "powerhouses of the cell", providing the main part of cellular energy via ATP generation, which is accomplished through oxidative phosphorylation from nutritional sources [45]. They control cell survival and death by regulating both energy metabolism and apoptotic pathways and contribute to many cellular functions, including intracellular calcium homeostasis, alteration of the cellular reduction-oxidation potential, cell cycle regulation and synaptic plasticity [46]. Mitochondrial dysfunction has been proposed as an underlying mechanism in the early stages of $\mathrm{AD}[47,48]$. We recently summarized evidence from ageing and Alzheimer models showing that the harmful trio "ageing, $A \beta$ and tau protein" triggers mitochondrial dysfunction through a number of pathways, such as impairment of oxidative phosphorylation, elevation of reactive oxygen species production and interaction with mitochondrial proteins, contributing to the development and progression of the disease [13, 49].

Mitochondria and neurosteroidogenesis are also closely linked since mitochondria contain the first enzyme involved in steroidogenesis, the cytochrome P450 cholesterol side chain cleavage enzyme (P450scc) located at the inner side of the mitochondrial membrane which is responsible for the conversion of cholesterol to pregnenolone (PREG). The first step of neurosteroidogenesis is the transfer of cholesterol from the outer to the inner mitochondrial membrane. It is also the rate-limiting step in the production of neurosteroids because the ability of cholesterol to enter into mitochondria to be available to the P450scc will determine the efficiency of steroidogenesis [50]. Free cholesterol accumulates outside of mitochondria and binds to the steroidogenic acute regulatory protein, a hormone-induced mitochondriatargeted protein that initiates cholesterol transfer into mitochondria. Then, molecules are transported inside mitochondria by a protein complex including translocator proteins (TSPO), a cholesterol-binding mitochondrial protein also known under the name of peripheral-type benzodiazepine receptor, which permits cholesterol transfer into mitochondria and subsequent steroid formation.

It has been shown that TSPO is up-regulated in the postmortem brain of $\mathrm{AD}$ patients, resulting in an increased level of PREG in the hippocampal region of those brains [50]. Interestingly, the level of 22R-hydroxycholesterol, a steroid intermediate in the conversion of cholesterol to PREG, was found at lower levels in the $\mathrm{AD}$ brain compared to the control, which suggests that TSPO does not function normally in Alzheimer patients [33, 51].

From an energetic point of view, it is known that steroids such as oestrogen can regulate mitochondrial metabolism by increasing the expression of glucose transporter subunits and by regulating some enzymes involved in the tricarboxylic acid cycle (TCA cycle) as well as glycolysis, such as the hexokinase, phosphofructokinase, pyruvate and malate dehydrogenase [41, 52], which leads to improved glucose utilization by cells $[11,44]$ (Fig. 2).

Oestrogens seem to be able to up-regulate genes coding for some electron transport chain components present in nuclear and in mitochondrial DNA [53, 54]. In fact, an oestrogen-induced increased expression of some subunits of mitochondrial complex I (CI), cytochrome c oxidase (complex IV or CIV) and F1 subunit of ATP synthase was observed [41, 42, 52]. Furthermore, treatment of ovariectomized female rats with oestradiol induced an increase of mitochondrial respiratory function in the brain with regard to an enhancement of $\mathrm{O}_{2}$ consumption coupled to an increased activity of cytochrome c oxidase [53]. Thus, oestrogen seems to enhance the general metabolism in cells, but besides, it seems also able to directly protect mitochondria against oxidative stress-induced injury [52]. Thus, incubation of isolated mitochondria from the rat brain with oestradiol leads to a decrease of $\mathrm{H}_{2} \mathrm{O}_{2}$ production by this organelle coupled with an increase of the mitochondrial membrane potential (MMP). Furthermore, it has been proposed that its phenolic A ring could allow oestradiol to intercalate into the mitochondrial membrane and to avoid lipid peroxidation occurring in stress condition [54], which could be responsible for the stabilization of the MMP. Moreover, oestradiol seems to prevent the release of cytochrome $\mathrm{c}$ by mitochondria (a mechanism known to induce apoptosis of cells by activating the caspase cascade in the cytoplasm), a mechanism increasing the efficiency of the respiratory chain [52].

Finally, another oestrogen signalling pathway avoiding the negative effects of oxidative stress is the one regulating 


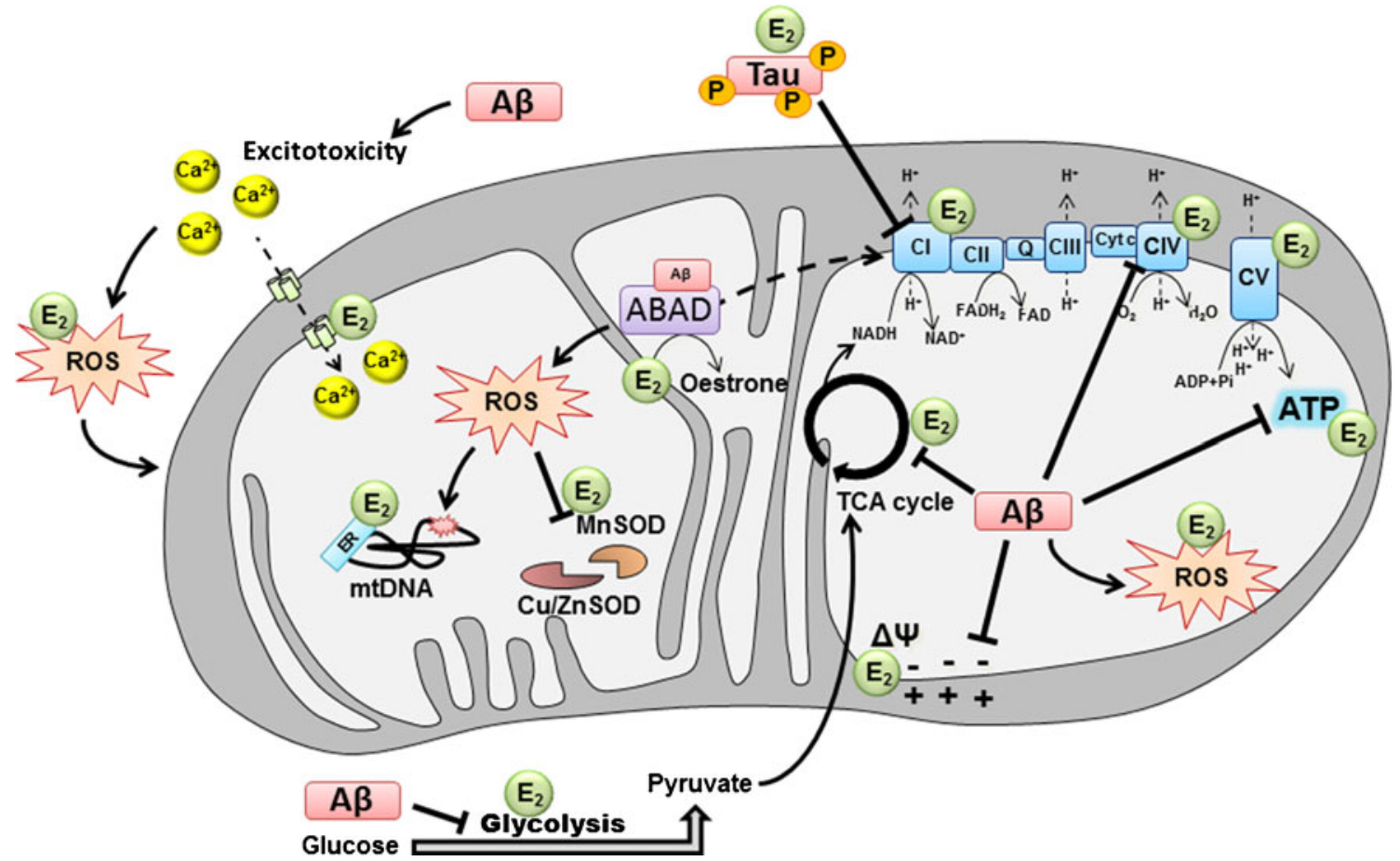

Fig. 2 Modulation of mitochondrial function by $A \beta$, hyperphosphorylated tau and oestradiol. In $\mathrm{AD}$, mitochondrial dysfunction was found to be a central pathological mechanism which occurs already at early stages of the disease. On one hand, studies showed that amyloid- $\beta$ peptide $(A \beta)$ can be responsible of metabolic impairments, such as the decrease of glucose consumption observed in the $\mathrm{AD}$ brain as well as the calcium-induced excitotoxicity in neurons. It has been found that hyperphosphorylated tau and $A \beta$ are able to impair mitochondrial respiration by inhibiting the ETC CI and CIV, respectively, inducing decreased oxygen consumption, decreased ATP production and increased ROS level. This oxidative stress induced by ETC dysfunction can surpass cellular and mitochondrial scavenger (MnSOD, Cu/ ZnSOD) and impacts on MMP as well as mitochondrial DNA (mtDNA). On the other hand, it has been shown that oestradiol can

calcium homeostasis by inducing mitochondrial sequestration of cytosolic calcium [42, 54]. In fact, an imbalance of calcium regulation can lead to an increase of ROS production by activating the enzyme nitric oxide synthase, which can in turn sensitize neural cells to oxidative damage. It has been shown that an oestradiol treatment of primary hippocampal neurons was able to potentiate glutamatergic response via NMDA receptor which resulted in an increased influx of calcium in cells. This effect was coupled to an induction of mitochondrial sequestration of cytosolic calcium and an increase of the mitochondrial calcium load tolerability thereby avoiding calcium-induced excitotoxicity as well as promoting cell survival.

Taken together, all those different findings indicate that oestrogen might be able to compensate deficits and injuries that occur in $\mathrm{AD}$, namely mitochondrial respiration impairments, enhanced ROS production, excitotoxicity and, more generally, metabolic deficits (Fig. 2). More recently, new light has been shed on a mitochondrial enzyme that is able to increase glucose utilization by cells as well as ETC activity, stabilize the MMP and prevent ROS production and calcium-induced excitotoxicity. In the graph, $E_{2}$ designates where oestradiol potentially acts on mitochondria to compensate $A \beta$-induced toxicity. In turn, $A \beta$ seems to be able to impact oestradiol metabolism in mitochondria, since it can be directly linked to the mitochondrial enzyme ABAD and possibly modulates its enzymatic activity (such as the reversible conversion of oestradiol to oestrone) and non-enzymatic activity (mitochondrial RNAse P). $A B A D \mathrm{~A} \beta$-binding alcohol dehydrogenase, $C I$ complex I, $C I I$ complex II, CIII complex III, $C I V$ complex IV, $C V$ complex V, cyt c cytochrome c, $\mathrm{Cu} / \mathrm{Zn} S O D$ copper/zinc superoxide dismutase, $M n S O D$ manganese superoxide dismutase, TCA tricyclic acid, $E_{2}$ oestradiol, $R O S$ reactive oxygen species, $m t D N A$ mitochondrial DNA, ER oestrogen receptor

directly bind $A \beta$ peptide and in which one of the main substrate is $17 \beta$-oestradiol [55]. This enzyme is known under the name of $17 \beta$-hydroxysteroid dehydrogenase type 10 (17 $\beta$-HSD) or $A \beta$-binding alcohol dehydrogenase (ABAD).

\section{ABAD, Oestradiol and A $\beta$-Induced Mitochondrial} Impairment

ABAD belongs to the alcohol dehydrogenase family, and it is responsible for the reversible oxido/reduction of several substrates including linear alcohols and steroids, such as $17 \beta$ oestradiol, using $\mathrm{NAD}^{+}$as cofactor [56]. Under normal conditions (without $A \beta$ ), this enzyme plays a role in the regulation of metabolic homeostasis, and its overexpression improved cell viability and ATP content [57]. It has been shown that $\mathrm{ABAD}$ is up-regulated in brains of $\mathrm{AD}$ mice as well as $\mathrm{AD}$ patients [57,58], and it has been suggested that the binding of $A \beta$ changes the conformation of the enzyme, which seems to exacerbate mitochondrial dysfunction induced by $\mathrm{A} \beta$. 
More recently, studies performed in transgenic mice models of $\mathrm{AD}$ showed that behavioural stress or depletion of ovarian hormones by ovariectomy exacerbated mitochondrial dysfunction, aggravated plaque pathology and increased $\mathrm{ABAD}$ expression in the brain $[59,60]$. Furthermore, double transgenic mice overexpressing mutant APP and ABAD present an earlier onset of cognitive impairment and histopathological changes when compared to APP mice [49], suggesting that $\mathrm{A} \beta-\mathrm{ABAD}$ interaction is an important mechanism underlying $A \beta$ toxicity. This hypothesis is supported by a study from Yao and collaborators who recently showed that inhibition of $A \beta-$ ABAD interaction by a decoy peptide can restore mitochondrial deficits (activity of mitochondrial respiratory complexes, ROS level) and improve neuronal and cognitive function [60].

New interesting findings of our group seem to go in the same way with regard to the use of a novel small ABADspecific compound inhibitor (AG18051) by investigating the role of this enzyme in $A \beta$ toxicity in human SH-SY5Y cells treated for 5 days with $A \beta_{1-42} 0.5$ uM [61]. The crystal structure of human ABAD in presence of AG18051 showed that the inhibitor formed a covalent link with the $\mathrm{NAD}^{+}$ cofactor and occupied the substrate-binding site of the enzyme [62]. Thus, the inhibitor was able to prevent $A \beta$ induced cell death and significantly normalized metabolic functions impaired by $\mathrm{A} \beta$, such as cytosolic and mitochondrial ROS as well as mitochondrial respiration. Furthermore, it was able to restore oestradiol levels which were reduced after treatment with $\mathrm{A} \beta[31,61]$. What is interesting to note is that the apparent protective effects of the ABAD inhibitor seem to be independent on its interaction with $A \beta$. In fact, a 24-h pre-treatment with AG18051, before the incubation of cells with $A \beta_{1-42}$, was sufficient to prevent cell death, normalize ROS production and restore mitochondrial respiration. Regarding oestradiol level, we previously showed that it decreased in the cytosol and increased in isolated mitochondria of SH-SY5Y cells after 5 days of treatment with $A \beta$ [49]. The ABAD inhibitor normalized the oestradiol level in the cytosol [61], and preliminary data of our group suggest a similar effect in isolated mitochondria (unpublished data). Thus, we propose the following model of mode of action: $A B A D$ inhibitor is able to block $A \beta$ toxicity by changing $\mathrm{ABAD}$ configuration, which disables the binding of $A \beta$ thus preventing its toxic effects (Fig. 3). The action of $\mathrm{ABAD}$ on the electron transport chain (ETC) is still unclear, but the potential role of ABAD as mitochondrial RNAse $\mathrm{P}$ directly links $\mathrm{ABAD}$ to the production of mitochondrial ETC proteins and ROS generation [63]. Notably, AG18051 was able to normalize also this function of ABAD since mitochondrial respiration was restored, but the underlying mechanisms still remain unclear [61].

Thus, the interplay between ABAD, oestradiol and mitochondria may be a very interesting lead to follow in the future to decode $A \beta$-induced mitochondrial toxicity and explore therapeutic strategies of ABAD inhibition.

\section{Conclusion}

It is still debated whether oestrogen treatment after menopause could result in improved cognitive function in women. This debate is based on many animal and cell culture data showing that oestrogens can positively affect the ageing and $\mathrm{AD}$ brain. It was recognized from former studies that oestrogen depletion in post-menopausal women represents a significant risk factor for the development of AD and that an oestrogen replacement therapy may decrease this risk and even delay disease progression [64, 65]. However, large treatment trials showed negative effects of long-term
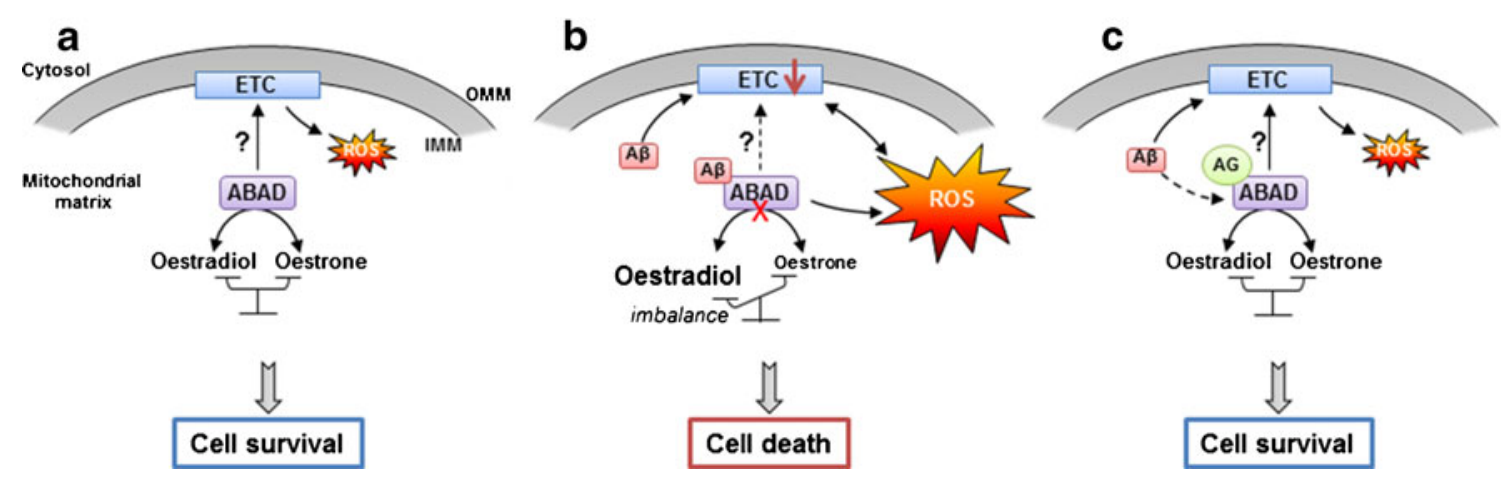

Fig. $3 \mathrm{~A} \beta, \mathrm{ABAD}$ and mitochondria: modes of interactions. a Under normal conditions, $\mathrm{ABAD}$ is responsible of the reversible oxido/reduction of linear alcohols and steroids, such as the reversible conversion from oestradiol to oestrone. Its potential function as an RNAse P could also be important for the good functioning of the mitochondrial ETC. b Under AD-relevant pathological conditions, $A \beta$ can directly bind the mitochondrial enzyme ABAD, changing the configuration of the enzyme which seems to inhibit its activity and creates an imbalance between oestradiol and oestrone. $\mathrm{A} \beta$-induced $\mathrm{ABAD}$ misfolding can impact ETC functioning and increase, directly or indirectly, ROS production, which lead to cell death. c In the presence of AG18051 (AG), the binding of $\mathrm{A} \beta$ to $\mathrm{ABAD}$ is inhibited, normalizing oestradiol level, ROS production, ETC activity, and improves cell survival. $A B A D \mathrm{~A} \beta$-binding alcohol dehydrogenase, $I M M$ inner mitochondrial membrane, $O M M$ outer mitochondrial membrane 
treatment with oestrogens in older women. Above all, results from the WHIMS including 4,532 post-menopausal woman aged over 68 years indicated a twofold increase in dementia after 4.2 years of hormonal treatment (p.o. treatment with premaxin plus medroxyprogesterone). In addition, the study indicated potential risks for breast cancer, pulmonary embolism and stroke $[66,67]$. Some attribute this failure to the synthetic nature of the hormones used in the WHIMS trial, since in vitro studies support a beneficial role of oestradiol and progesterone, but not of medroxyprogesterone used in the WHIMS [68, 69]. Of note, medroxyprogesterone is not metabolized to $3 \alpha, 5 \alpha$-THP and can inhibit conversion of PROG to $3 \alpha, 5 \alpha$-THP [70]. Similarly, oestradiol, PROG or $3 \alpha, 5 \alpha-$ THP, but not medroxyprogesterone, showed beneficial effects in ageing, seizure, cortical contusion, ischaemia and diabetic neuropathy models [38]. Another theory which tries to explain trial failure is the "critical window hypothesis", asking for the critical period where oestrogen might exert a neuroprotective effect [71]. This hypothesis is substantiated by animal research, e.g. mice which have undergone ovariectomy, but in which oestrogen treatment was delayed substantially by months (the equivalent of years in human terms), did not benefit by this, as the animals did which received treatment immediately after ovariectomy [72]. However, a recent metaanalysis [73] indicated, contrary to expectations, that age of women and duration of time relapsed when treatment was initiated since menopause did not significantly affect treatment outcome. Thus, natural oestradiol (E2) without a progestagen should represent the preferred treatment [73]. Furthermore, the oral route of drug delivery, being noninvasive in nature, is by far the most convenient and preferred route of administration in any acute or chronic treatment. Though oestradiol itself from conventional oral oestradiol formulations has the ability to cross the blood-brain barrier (BBB) and reach the brain, but a large oral dose is required to achieve therapeutic levels of oestradiol due to its nonspecificity for the brain. This non-specificity increases the peripheral drug burden and subsequently potentiates the risk of peripheral adverse effects. Furthermore, with specific regard to the brain-specific action of oestradiol as a neurosteroid, independently of its action in the periphery, other modes of administration (cyclical, nasal, polymer nanoparticles for oral delivery) need to be sought and investigated [74]. Alternatively, the true potential of phyto-oestrogens, like the soy isoflavones genistein, daidzein and glycitein, which activate the same neuroprotective pathways than oestrogens but with weak oestrogenic cellular effects that might be responsible for the lower prevalence of AD in Japanese living in their ethnic homeland compared to Japanese living in the USA [75], to beneficially modify disease processes should be studied in clinical trials [27]. In addition, the field could strongly benefit from the successful development of oestrogen derivates that have no unfavourable oestrogenic side effects. The successful use of oestrogen or oestrogen-analogue therapies to delay, prevent and/or treat $\mathrm{AD}$ will require additional research to optimize key parameters of therapy.

In this context, the interplay between $\mathrm{ABAD}$, oestradiol and mitochondria and accordingly ABAD inhibition might represent a further interesting lead to follow in the future. Knowledge acquired from these studies will eventually be applied to unravel the pathophysiology and to inform prevention and intervention strategies of $A D$.

Acknowledgments This work has been supported by a grant from the Swiss National Science Foundation (\#31000_122572) and Synapsis Foundation.

Conflict of Interest The authors declare that they have no conflict of interest.

Open Access This article is distributed under the terms of the Creative Commons Attribution License which permits any use, distribution, and reproduction in any medium, provided the original author(s) and the source are credited.

\section{References}

1. Corpechot C, Robel P, Axelson M, Sjovall J, Baulieu EE (1981) Characterization and measurement of dehydroepiandrosterone sulfate in rat brain. Proc Natl Acad Sci USA 78(8):4704-4707

2. Mensah-Nyagan AG, Do-Rego JL, Beaujean D, Luu-The V, Pelletier G, Vaudry H (1999) Neurosteroids: expression of steroidogenic enzymes and regulation of steroid biosynthesis in the central nervous system. Pharmacol Rev 51(1):63-81

3. Patte-Mensah C, Kibaly C, Boudard D, Schaeffer V, Begle A, Saredi S, Meyer L, Mensah-Nyagan AG (2006) Neurogenic pain and steroid synthesis in the spinal cord. J Mol Neurosci 28(1):1731. doi:10.1385/JMN:30:3:341

4. Plassart-Schiess E, Baulieu EE (2001) Neurosteroids: recent findings. Brain Res Rev 37(1-3):133-140

5. Tsutsui K (2008) Neurosteroids in the Purkinje cell: biosynthesis, mode of action and functional significance. Mol Neurobiol 37(2-3):116-125. doi:10.1007/s12035-008-8024-1

6. Schumacher M, Weill-Engerer S, Liere P, Robert F, Franklin RJ, Garcia-Segura LM, Lambert JJ, Mayo W, Melcangi RC, Parducz A, Suter U, Carelli C, Baulieu EE, Akwa Y (2003) Steroid hormones and neurosteroids in normal and pathological aging of the nervous system. Prog Neurobiol 71(1):3-29

7. Mensah-Nyagan AG, Kibaly C, Schaeffer V, Venard C, Meyer L, Patte-Mensah C (2008) Endogenous steroid production in the spinal cord and potential involvement in neuropathic pain modulation. J Steroid Biochem Mol Biol 109(3-5):286-293. doi:10.1016/j.jsbmb.2008.03.002

8. Foryst-Ludwig A, Kintscher U (2010) Metabolic impact of estrogen signalling through ERalpha and ERbeta. J Steroid Biochem Mol Biol 122(1-3):74-81. doi:10.1016/j.jsbmb.2010.06.012

9. Arnold S, Beyer C (2009) Neuroprotection by estrogen in the brain: the mitochondrial compartment as presumed therapeutic target. $\mathrm{J}$ Neurochem 110(1):1-11. doi:10.1111/j.1471-4159.2009.06133.x

10. Barron AM, Pike CJ (2012) Sex hormones, aging, and Alzheimer's disease. Front Biosci (Elite Ed) 4:976-997

11. Pike CJ, Carroll JC, Rosario ER, Barron AM (2009) Protective actions of sex steroid hormones in Alzheimer's disease. Front Neuroendocrinol 30(2):239-258. doi:10.1016/j.yfrne.2009.04.015 
12. Brookmeyer R, Johnson E, Ziegler-Graham K, Arrighi HM (2007) Forecasting the global burden of Alzheimer's disease. Alzheimers Dement 3(3):186-191. doi:10.1016/j.jalz.2007.04.381

13. Eckert A, Schmitt K, Gotz J (2011) Mitochondrial dysfunctionthe beginning of the end in Alzheimer's disease? Separate and synergistic modes of tau and amyloid-beta toxicity. Alzheimers Res Ther 3(2):15. doi:10.1186/alzrt74

14. Hy LX, Keller DM (2000) Prevalence of AD among whites: a summary by levels of severity. Neurology 55(2):198-204

15. Corder EH, Ghebremedhin E, Taylor MG, Thal DR, Ohm TG, Braak H (2004) The biphasic relationship between regional brain senile plaque and neurofibrillary tangle distributions: modification by age, sex, and APOE polymorphism. Ann N Y Acad Sci 1019:24-28. doi:10.1196/annals.1297

16. Barnes LL, Wilson RS, Bienias JL, Schneider JA, Evans DA, Bennett DA (2005) Sex differences in the clinical manifestations of Alzheimer disease pathology. Arch Gen Psychiatry 62(6):685691. doi:10.1001/archpsyc.62.6.685

17. Rosario ER, Chang L, Head EH, Stanczyk FZ, Pike CJ (2011) Brain levels of sex steroid hormones in men and women during normal aging and in Alzheimer's disease. Neurobiol Aging 32 (4):604-613. doi:10.1016/j.neurobiolaging.2009.04.008

18. Carroll JC, Rosario ER, Chang L, Stanczyk FZ, Oddo S, LaFerla FM, Pike CJ (2007) Progesterone and estrogen regulate Alzheimer-like neuropathology in female 3xTg-AD mice. J Neurosci 27(48):13357-13365. doi:10.1523/JNEUROSCI.2718-07.2007

19. Callahan MJ, Lipinski WJ, Bian F, Durham RA, Pack A, Walker LC (2001) Augmented senile plaque load in aged female beta-amyloid precursor protein-transgenic mice. Am J Pathol 158(3):1173-1177

20. Wang J, Tanila H, Puolivali J, Kadish I, van Groen T (2003) Gender differences in the amount and deposition of amyloidbeta in APPswe and PS1 double transgenic mice. Neurobiol Dis 14 (3):318-327

21. Sturchler-Pierrat C, Staufenbiel M (2000) Pathogenic mechanisms of Alzheimer's disease analyzed in the APP23 transgenic mouse model. Ann N Y Acad Sci 920:134-139

22. Hirata-Fukae C, Li HF, Hoe HS, Gray AJ, Minami SS, Hamada K, Niikura T, Hua F, Tsukagoshi-Nagai H, Horikoshi-Sakuraba Y, Mughal M, Rebeck GW, LaFerla FM, Mattson MP, Iwata N, Saido TC, Klein WL, Duff KE, Aisen PS, Matsuoka Y (2008) Females exhibit more extensive amyloid, but not tau, pathology in an Alzheimer transgenic model. Brain Res 1216:92-103. doi:10.1016/j.brainres.2008.03.079

23. Grueninger F, Bohrmann B, Czech C, Ballard TM, Frey JR, Weidensteiner C, von Kienlin M, Ozmen L (2010) Phosphorylation of Tau at S422 is enhanced by Abeta in TauPS2APP triple transgenic mice. Neurobiol Dis 37(2):294-306. doi:10.1016/ j.nbd.2009.09.004

24. Gotz J, Chen F, van Dorpe J, Nitsch RM (2001) Formation of neurofibrillary tangles in P3011 tau transgenic mice induced by Abeta 42 fibrils. Science 293(5534):1491-1495. doi:10.1126/science

25. Lewis J, Dickson DW, Lin WL, Chisholm L, Corral A, Jones G, Yen SH, Sahara N, Skipper L, Yager D, Eckman C, Hardy J, Hutton M, McGowan E (2001) Enhanced neurofibrillary degeneration in transgenic mice expressing mutant tau and APP. Science 293(5534):1487-1491. doi:10.1126/science. 1058189

26. Schuessel K, Leutner S, Cairns NJ, Muller WE, Eckert A (2004) Impact of gender on upregulation of antioxidant defence mechanisms in Alzheimer's disease brain. J Neural Transm 111(9):11671182. doi:10.1007/s00702-004-0156-5

27. Vina J, Lloret A (2010) Why women have more Alzheimer's disease than men: gender and mitochondrial toxicity of amyloidbeta peptide. J Alzheimers Dis 20(Suppl 2):S527-533. doi:10.3233/JAD-2010-100501

28. Schaeffer V, Patte-Mensah C, Eckert A, Mensah-Nyagan AG (2006) Modulation of neurosteroid production in human neuroblastoma cells by Alzheimer's disease key proteins. J Neurobiol 66(8):868881. doi:10.1002/neu.20267

29. Schaeffer V, Patte-Mensah C, Eckert A, Mensah-Nyagan AG (2008) Selective regulation of neurosteroid biosynthesis in human neuroblastoma cells under hydrogen peroxide-induced oxidative stress condition. Neuroscience 151(3):758-770. doi:10.1016/ j.neuroscience.2007.11.032

30. Olivieri G, Novakovic M, Savaskan E, Meier F, Baysang G, Brockhaus M, Muller-Spahn F (2002) The effects of betaestradiol on SHSY5Y neuroblastoma cells during heavy metal induced oxidative stress, neurotoxicity and beta-amyloid secretion. Neuroscience 113(4):849-855

31. Schaeffer V, Meyer L, Patte-Mensah C, Eckert A, Mensah-Nyagan AG (2008) Dose-dependent and sequence-sensitive effects of amyloid-beta peptide on neurosteroidogenesis in human neuroblastoma cells. Neurochem Int 52(6):948-955. doi:10.1016/ j.neuint.2008.01.010

32. Brown RC, Cascio C, Papadopoulos V (2000) Pathways of neurosteroid biosynthesis in cell lines from human brain: regulation of dehydroepiandrosterone formation by oxidative stress and betaamyloid peptide. J Neurochem 74(2):847-859

33. Brown RC, Han Z, Cascio C, Papadopoulos V (2003) Oxidative stress-mediated DHEA formation in Alzheimer's disease pathology. Neurobiol Aging 24(1):57-65

34. Griffin LD, Gong W, Verot L, Mellon SH (2004) Niemann-Pick type $\mathrm{C}$ disease involves disrupted neurosteroidogenesis and responds to allopregnanolone. Nat Med 10(7):704-711. doi:10.1038/nm1073

35. Smith CD, Wekstein DR, Markesbery WR, Frye CA (2006) 3alpha, 5alpha-THP: a potential plasma neurosteroid biomarker in Alzheimer's disease and perhaps non-Alzheimer's dementia. Psychopharmacology (Berl) 186(3):481-485. doi:10.1007/s00213-005-0186-1

36. Castellani RJ, Rolston RK, Smith MA (2010) Alzheimer disease. Dis Mon 56(9):484-546. doi:10.1016/j.disamonth.2010.06.001

37. Amtul Z, Wang L, Westaway D, Rozmahel RF (2010) Neuroprotective mechanism conferred by 17 beta-estradiol on the biochemical basis of Alzheimer's disease. Neuroscience 169(2):781786. doi:10.1016/j.neuroscience.2010.05.031

38. Frye CA, Walf AA (2008) Effects of progesterone administration and APPswe+PSEN1Deltae9 mutation for cognitive performance of mid-aged mice. Neurobiol Learn Mem 89(1):17-26. doi:10.1016/j.nlm.2007.09.008

39. Goodenough S, Schleusner D, Pietrzik C, Skutella T, Behl C (2005) Glycogen synthase kinase 3beta links neuroprotection by 17beta-estradiol to key Alzheimer processes. Neuroscience 132 (3):581-589. doi:10.1016/j.neuroscience.2004.12.029

40. Chen S, Wang JM, Irwin RW, Yao J, Liu L, Brinton RD (2011) Allopregnanolone promotes regeneration and reduces betaamyloid burden in a preclinical model of Alzheimer's disease. PLoS One 6(8):e24293. doi:10.1371/journal.pone.0024293

41. Simpkins JW, Yi KD, Yang SH, Dykens JA (2010) Mitochondrial mechanisms of estrogen neuroprotection. Biochim Biophys Acta 1800(10):1113-1120. doi:10.1016/j.bbagen.2009.11.013

42. Nilsen J (2008) Estradiol and neurodegenerative oxidative stress. Front Neuroendocrinol 29(4):463-475. doi:10.1016/ j.yfrne.2007.12.005

43. Borras C, Sastre J, Garcia-Sala D, Lloret A, Pallardo FV, Vina J (2003) Mitochondria from females exhibit higher antioxidant gene expression and lower oxidative damage than males. Free Radic Biol Med 34(5):546-552

44. Brinton RD (2008) Estrogen regulation of glucose metabolism and mitochondrial function: therapeutic implications for prevention of Alzheimer's disease. Adv Drug Deliv Rev 60(13-14):1504-1511. doi:10.1016/j.addr.2008.06.003

45. Scheffler IE (2001) A century of mitochondrial research: achievements and perspectives. Mitochondrion 1(1):3-31 
46. Mattson MP, Gleichmann M, Cheng A (2008) Mitochondria in neuroplasticity and neurological disorders. Neuron 60(5):748-766. doi:10.1016/j.neuron.2008.10.010

47. Keil U, Bonert A, Marques CA, Scherping I, Weyermann J, Strosznajder JB, Muller-Spahn F, Haass C, Czech C, Pradier L, Muller WE, Eckert A (2004) Amyloid beta-induced changes in nitric oxide production and mitochondrial activity lead to apoptosis. J Biol Chem 279(48):50310-50320. doi:10.1074/ jbc.M405600200

48. Leuner K, Schutt T, Kurz C, Eckert SH, Schiller C, Occhipinti A, Mai S, Jendrach M, Eckert GP, Kruse SE, Palmiter RD, Brandt U, Drose S, Wittig I, Willem M, Haass C, Reichert AS, Muller WE (2012) Mitochondrion-derived reactive oxygen species lead to enhanced amyloid beta formation. Antioxid Redox Signal 16 (12):1421-1433. doi:10.1089/ars.2011.4173

49. Schmitt K, Grimm A, Kazmierczak A, Strosznajder JB, Gotz J, Eckert A (2011) Insights into mitochondrial dysfunction: aging amyloid-beta and tau - a deleterious trio. Antioxid Redox Signal. doi:10.1089/ars.2011.4400

50. Rone MB, Fan J, Papadopoulos V (2009) Cholesterol transport in steroid biosynthesis: role of protein-protein interactions and implications in disease states. Biochim Biophys Acta 1791(7):646-658. doi:10.1016/j.bbalip.2009.03.001

51. Papadopoulos V, Lecanu L, Brown RC, Han Z, Yao ZX (2006) Peripheral-type benzodiazepine receptor in neurosteroid biosynthesis, neuropathology and neurological disorders. Neuroscience 138(3):749-756. doi:10.1016/j.neuroscience.2005.05.063

52. Borras C, Gambini J, Lopez-Grueso R, Pallardo FV, Vina J (2010) Direct antioxidant and protective effect of estradiol on isolated mitochondria. Biochim Biophys Acta 1802(1):205-211. doi:10.1016/j.bbadis.2009.09.007

53. Irwin RW, Yao J, Hamilton RT, Cadenas E, Brinton RD, Nilsen J (2008) Progesterone and estrogen regulate oxidative metabolism in brain mitochondria. Endocrinology 149(6):3167-3175. doi:10.1210/en.2007-1227

54. Simpkins JW, Dykens JA (2008) Mitochondrial mechanisms of estrogen neuroprotection. Brain Res Rev 57(2):421-430. doi:10.1016/j.brainresrev.2007.04.007

55. Yan SD, Fu J, Soto C, Chen X, Zhu H, Al-Mohanna F, Collison K, Zhu A, Stern E, Saido T, Tohyama M, Ogawa S, Roher A, Stern D (1997) An intracellular protein that binds amyloid-beta peptide and mediates neurotoxicity in Alzheimer's disease. Nature 389 (6652):689-695. doi:10.1038/39522

56. Yang SY, He XY, Schulz H (2005) Multiple functions of type 10 17beta-hydroxysteroid dehydrogenase. Trends Endocrinol Metab 16(4):167-175. doi:10.1016/j.tem.2005.03.006

57. Yan SD, Stern DM (2005) Mitochondrial dysfunction and Alzheimer's disease: role of amyloid-beta peptide alcohol dehydrogenase (ABAD). Int J Exp Pathol 86(3):161-171. doi:10.1111/ j.0959-9673.2005.00427.x

58. Kristofikova Z, Bockova M, Hegnerova K, Bartos A, Klaschka J, Ricny J, Ripova D, Homola J (2009) Enhanced levels of mitochondrial enzyme 17beta-hydroxysteroid dehydrogenase type 10 in patients with Alzheimer disease and multiple sclerosis. Mol Biosyst 5(10):1174-1179. doi:10.1039/b904799a

59. Seo JS, Lee KW, Kim TK, Baek IS, Im JY, Han PL (2011) Behavioral stress causes mitochondrial dysfunction via ABAD up-regulation and aggravates plaque pathology in the brain of a mouse model of Alzheimer disease. Free Radic Biol Med 50 (11):1526-1535. doi:10.1016/j.freeradbiomed.2011.02.035

60. Yao J, Irwin R, Chen S, Hamilton R, Cadenas E, Brinton RD (2011) Ovarian hormone loss induces bioenergetic deficits and mitochondrial beta-amyloid. Neurobiol Aging. doi:10.1016/ j.neurobiolaging.2011.03.001

61. Lim YA, Grimm A, Giese M, Mensah-Nyagan AG, Villafranca JE, Ittner LM, Eckert A, Gotz J (2011) Inhibition of the mitochondrial enzyme $\mathrm{ABAD}$ restores the amyloid-beta-mediated deregulation of estradiol. PLoS One 6(12):e28887. doi:10.1371/journal.pone.0028887

62. Kissinger CR, Rejto PA, Pelletier LA, Thomson JA, Showalter RE, Abreo MA, Agree CS, Margosiak S, Meng JJ, Aust RM, Vanderpool D, Li B, Tempczyk-Russell A, Villafranca JE (2004) Crystal structure of human $\mathrm{ABAD} / \mathrm{HSD} 10$ with a bound inhibitor: implications for design of Alzheimer's disease therapeutics. J Mol Biol 342(3):943952. doi:10.1016/j.jmb.2004.07

63. Holzmann J, Rossmanith W (2009) tRNA recognition, processing, and disease: hypotheses around an unorthodox type of RNase P in human mitochondria. Mitochondrion 9(4):284-288. doi:10.1016/ j.mito.2009.03.008

64. Paganini-Hill A, Henderson VW (1996) Estrogen replacement therapy and risk of Alzheimer disease. Arch Intern Med 156 (19):2213-2217

65. Tang MX, Jacobs D, Stern Y, Marder K, Schofield P, Gurland B, Andrews H, Mayeux R (1996) Effect of oestrogen during menopause on risk and age at onset of Alzheimer's disease. Lancet 348 (9025):429-432. doi:10.1016/S0140-6736(96)03356-9

66. Anderson GL, Limacher M, Assaf AR, Bassford T, Beresford SA, Black H, Bonds D, Brunner R, Brzyski R, Caan B, Chlebowski R, Curb D, Gass M, Hays J, Heiss G, Hendrix S, Howard BV, Hsia J, Hubbell A, Jackson R, Johnson KC, Judd H, Kotchen JM, Kuller L, LaCroix AZ, Lane D, Langer RD, Lasser N, Lewis CE, Manson J, Margolis K, Ockene J, O'Sullivan MJ, Phillips L, Prentice RL, Ritenbaugh C, Robbins J, Rossouw JE, Sarto G, Stefanick ML, Van Horn L, Wactawski-Wende J, Wallace R, Wassertheil-Smoller S (2004) Effects of conjugated equine estrogen in postmenopausal women with hysterectomy: the Women's Health Initiative randomized controlled trial. JAMA 291(14):1701-1712. doi:10.1001/ jama.291.14.1701

67. Rossouw JE, Anderson GL, Prentice RL, LaCroix AZ, Kooperberg C, Stefanick ML, Jackson RD, Beresford SA, Howard BV, Johnson KC, Kotchen JM, Ockene J (2002) Risks and benefits of estrogen plus progestin in healthy postmenopausal women: principal results from the Women's Health Initiative randomized controlled trial. JAMA 288(3):321-333

68. Goodman Y, Bruce AJ, Cheng B, Mattson MP (1996) Estrogens attenuate and corticosterone exacerbates excitotoxicity, oxidative injury, and amyloid beta-peptide toxicity in hippocampal neurons. J Neurochem 66(5):1836-1844

69. Nilsen J, Brinton RD (2002) Impact of progestins on estrogeninduced neuroprotection: synergy by progesterone and 19norprogesterone and antagonism by medroxyprogesterone acetate. Endocrinology 143(1):205-212

70. Penning TM, Sharp RB, Krieger NR (1985) Purification and properties of 3 alpha-hydroxysteroid dehydrogenase from rat brain cytosol. Inhibition by nonsteroidal anti-inflammatory drugs and progestins. J Biol Chem 260(28):15266-15272

71. Henderson VW, Brinton RD (2010) Menopause and mitochondria: windows into estrogen effects on Alzheimer's disease risk and therapy. Prog Brain Res 182:77-96. doi:10.1016/S0079-6123(10) 82003-5

72. Gibbs RB (2010) Estrogen therapy and cognition: a review of the cholinergic hypothesis. Endocr Rev 31(2):224-253. doi:10.1210/ er.2009-0036

73. Hogervorst E, Bandelow S (2010) Sex steroids to maintain cognitive function in women after the menopause: a meta-analyses of treatment trials. Maturitas 66(1):56-71. doi:10.1016/j.maturitas. 2010.02.005

74. Mittal G, Carswell H, Brett R, Currie S, Kumar MN (2011) Development and evaluation of polymer nanoparticles for oral delivery of estradiol to rat brain in a model of Alzheimer's pathology. J Control Release 150(2):220-228. doi:10.1016/j.jconrel.2010.11.013

75. Grant WB (1999) Dietary links to Alzheimer's disease: 1999 update. J Alzheimers Dis 1(4-5):197-201 